\title{
Impact of Multi-Interface Surfactant Adsorption on Wettability in Dense Nonaqueous Phase Liquid Systems
}

\author{
Hsin-Lan $\mathrm{Hsu}^{1, *}$ and Avery H. Demond ${ }^{2}$ \\ ${ }^{1}$ Energy and Environment Research Laboratories, Industrial Technology Research Institute, Hsinchu, Taiwan. \\ ${ }^{2}$ Department of Civil and Environmental Engineering, The University of Michigan, Ann Arbor, Michigan.
}

Received: July 8, 2009 Accepted in revised form: October 22, 2009

\begin{abstract}
The wettability, and hence the distribution and transport, of dense nonaqueous phase liquid (DNAPL) wastes in the subsurface is strongly affected by surfactants that are present in the wastes. To understand their impact, this work examined the dependence of the contact angle of quartz/tetrachloroethylene (PCE)/water systems containing the anionic surfactant Aerosol OT (AOT) or/and the nonionic surfactant hexaoxyethylene glycol mono-ndodecyl ether $\left(\mathrm{C}_{12} \mathrm{E}_{6}\right)$ on the surfactants' adsorption at both the PCE/water and silica/water interfaces. Results showed that $\mathrm{C}_{12} \mathrm{E}_{6}$ enhanced oil wetness at low $\mathrm{pH}$. However, the system reverted to water-wet upon the addition of AOT, which by itself, did not alter the wettability of the system. To mechanistically explain such behavior, it was proposed that, based on measurements of adsorption onto quartz and calculations of surface excess using an equation-of-state approach, the increased oil-wetness in systems containing $\mathrm{C}_{12} \mathrm{E}_{6}$ is due to the entropy-driven attraction between the oxyethylene groups of the adsorbed $\mathrm{C}_{12} \mathrm{E}_{6}$ at both the PCE/water and water/silica interfaces. Addition of AOT reduced the adsorbed $\mathrm{C}_{12} \mathrm{E}_{6}$ at both interfaces, lowering the attraction between PCE and silica. Thus, a consideration of surfactant adsorption at both interfaces, and the subsequent interaction between the molecules sorbed at both interfaces, is critical to explaining the wettability behavior of waste DNAPLs.
\end{abstract}

Key words: surface excess; wettability; DNAPLs; adsorption; surfactant

\section{Introduction}

$\mathbf{R}$ ECENT REPORTS UNDERSCORE the fact that the presence of dense nonaqueous phase liquids (DNAPLs), such as tetrachloroethylene (PCE) and trichloroethylene (TCE), remains one of most vexing issues confounding the cleanup of hazardous waste sites (National Research Council, 2004). The distribution of DNAPLs in the subsurface and the remediation efficiency are strongly affected by the system's wettability (Dwarakanath et al., 2002; O'Carroll et al., 2004), which is significantly different from their laboratory-grade counterparts (Harrold et al., 2001; Dwarakanath et al., 2002) because wastes often contain surface-active components that have the potential to adsorb at the interfaces and change the interfacial properties of the system. For example, organic bases render silica more oil-wet at low $\mathrm{pH}$, which was attributed to the adsorption of the bases' cationic form (Standal et al., 1999; Lord et al., 2000). When the total concentration of an organic base was fixed, Lord et al. (2000) observed that the contact angle on quartz increased with increasing $\mathrm{pH}$ and then decreased when the $\mathrm{pH}$ approached the $\mathrm{pKa}$ of the organic base.

${ }^{*}$ Corresponding author: Energy and Environment Research Laboratories, Industrial Technology Research Institute, Rm. 210, Bldg. 6, 321 Kuang Fu Road, Sec. 2, Hsinchu, Taiwan 300. Phone: 886-35732683; Fax: 886-3-5732890; E-mail: hlhsu@itri.org.tw
They proposed that, at low $\mathrm{pH}$, the limiting factor was the number of negatively charged sites on the quartz surface, so the increase of the contact angle with $\mathrm{pH}$ was a result of the increase in the number of sites. When the $\mathrm{pH}$ approached the pKa of the organic base, however, more organic base converted to its neutral form, which preferentially partitioned into the organic liquid. Thus, the quantity of protonated base became the limiting factor and the organic base adsorption density decreased, despite the fact that the quartz surface was more negatively charged. Similar wettability changes were observed with cationic surfactants, which rendered the silica surface more oil-wet because the adsorbed surfactants neutralized the negative surface charge, reducing the surface's hydrophilicity (Demond et al., 1994). In contrast to organic bases, organic acids either in their neutral form or in the anionic form do not adsorb on the negatively charged silica due to electrostatic repulsion. Thus, they do not alter the wettability (Lord et al., 1997; Standal et al., 1999).

Although the above studies interpreted wettability changes based on surfactant adsorption at the water/silica interface, others focus on surfactant adsorption at the oil/water interface, or the so-called surface excess. For example, in a crude oil/water/silica system (Buckley et al., 1987; Dubey and Doe, 1993) or creosote/water/silica system (Zheng et al., 2001), silica was oil-wet at low $\mathrm{pH}$ and water-wet at high $\mathrm{pH}$, and the $\mathrm{pH}$ of wettability reversal often occurred slightly above the 
isoelectric points of the emulsions. Dubey and Doe (1993) thus proposed that the wettability change can be attributed to the electrostatic interaction and van der Waal forces between the silica surface and the surface-active species at the oil/water interface. Zheng et al. (2001) further evaluated this hypothesis quantitatively by calculating the $\mathrm{pH}$ of wettability reversal using a disjoining pressure model combining electrostatic and van der Waal interactions. Their results showed a reasonable agreement with the experimental measurements, suggesting that the surface-active species at the oil/water interface play an important role in determining the wettability.

Based on these studies, it seems that surfactant adsorption at the solid/water and at the oil/water interfaces can both affect wettability. The fact that considering surfactant adsorption at one single interface proved to be sufficient in the above-cited studies is perhaps due to the negligibility of the surface-active species at the other interface. For example, the surface-active species in crude oils or creosote are mainly large-molecular-weight compounds such as asphaltenes (Speight, 1991), whose adsorption at the oil/water interface is appreciable but insignificant at the water/silica interface. Yet, in complex mixtures of surfactants, such an approach may be untenable. If there is appreciable surfactant sorption at both interfaces, there may be additional interactions between the adsorbed surfactant molecules at the two interfaces, which might play a role in the determination of wettability.

The studies above do not consider the possible presence of nonionic surfactants (the second most commonly used class of surfactants after anionics) (Myers, 1992), which may very likely be present in DNAPL wastes due to their frequent use as detergents in dry-cleaning solvents. Therefore, the objective of this work is to examine the interaction among surfactant molecules at both the DNAPL/water and solid/water interfaces in systems containing typical industrial surfactants to assess whether surfactant adsorption at both interfaces affect wettability. By measuring the contact angles and the surfactant adsorption at both the solid/water $(\mathrm{s} / \mathrm{w})$ and organic liquid/water $(\mathrm{o} / \mathrm{w})$ interfaces in a system composed of a chlorinated organic liquid, a nonionic or/and an anionic surfactant, an appropriate interpretation of wettability changes is developed. Because most industrial DNAPL wastes are mixtures containing multiple kinds of surfactants, the wettability characteristics of the mixed surfactant systems studied here provide mechanistic insight into the anecdotally reported behavior of real DNAPL wastes in the environment, thus allowing for better a informed design of DNAPL waste site remediation.

\section{Materials and Methods}

\section{Sample preparation}

To create the synthetic DNAPL wastes, solutions of Aerosol OT (AOT, 100\% solid) or hexaoxyethylene glycol mono-ndodecyl ether $\left(\mathrm{C}_{12} \mathrm{E}_{6}\right.$, Nikkol Chemical, Tokyo, Japan) or both were prepared in $4 \mathrm{~mL}$ PCE [high-performance liquid chromatography (HPLC) grade] and then mixed with $30 \mathrm{~mL}$ water containing $0.01 \mathrm{M} \mathrm{NaCl}$ at various $\mathrm{pH}$ values. Concentrations, denoted by $[\mathrm{AOT}]_{\mathrm{T}}$ or $\left[\mathrm{C}_{12} \mathrm{E}_{6}\right]_{\mathrm{T}}$, indicate the total added moles of AOT or $\mathrm{C}_{12} \mathrm{E}_{6}$ divided by the volume of PCE. AOT was selected as it is a popular anionic surfactant in grease formulations and in commercial dry-cleaning solvents. $\mathrm{C}_{12} \mathrm{E}_{6}$ was selected as it contains a common hydrophilic group in nonionic surfactants. After mixing for 3 days, which experience demonstrated was long enough to reach equilibrium (Cowell et al., 2000), samples were centrifuged to break down the emulsions and then the final $\mathrm{pH}$ values were recorded.

\section{Contact angle measurements}

To measure the contact angle, a clean quartz slide (Quartz Scientific, Fairport Harbor, $\mathrm{OH}$, USA) was placed in the preequilibrated aqueous phase of the sample for a week, after which a sessile drop of the PCE solution was placed on the slide. A series of pictures of each sessile drop were taken over $30 \mathrm{~min}$ to confirm equilibrium and the receding contact angles were measured using axisymmetric drop shape analysis (Cheng, 1990). The contact angle values reported here represent the average of four drops and are receding angles, measured through the aqueous phase.

\section{Adsorption isotherm at the $s / w$ interface}

The adsorption isotherm of the surfactants on quartz powder at various $\mathrm{pH}$ values was measured, based on depletion of the surfactants from the aqueous phase. A known mass of quartz powder (\#40, U.S. Silica, BET surface area $=$ $1.084 \mathrm{~m}^{2} / \mathrm{g}$ ) was mixed with a surfactant solution and then shaken for 2 days, after which the mixture was centrifuged and the equilibrium $\mathrm{pH}$ was recorded. The surfactant concentration was analyzed using a reversed-phase highperformance liquid chromatograph (1015 HPLC), equipped with a Hypersil ODS guard column and a Sedere SEDEX 55 evaporative light-scattering detector operated at $40^{\circ} \mathrm{C}$. Equilibrium was equated with a change in bulk phase concentration of less than $0.3 \%$ over a week. All experiments were conducted at room temperature, $23-25^{\circ} \mathrm{C}$.

\section{Surface excess at the $0 / w$ interface}

To obtain the surface excess of surfactants at the PCE/water interface, an approach developed by Blankschtein and his coworkers (Nikas et al., 1992; Mulqueen and Blankschtein, $1999,2002)$ was adapted, the details of which can be found in the Supporting Information. In brief, the surface excess of surfactant $i, \Gamma_{i}$, is related to the surface pressure, $\Pi$, defined as the interfacial tension reduction upon the addition of surfactants, by Equation (1), where the first term represents the steric (or volume-excluded) effects, the second term represents the interaction between surfactant hydrophobic tails, and the last two terms represent the electrostatic forces between the ionic surfactant hydrophilic groups:

$$
\begin{aligned}
\Pi= & k_{B} T\left(\frac{\sum_{i} \Gamma_{i}}{1-\sum_{i} \Gamma_{i} a_{i}}+\frac{\pi\left(\sum_{i} \Gamma_{i} r_{i}\right)^{2}}{\left(1-\Gamma_{i} a_{i}\right)^{2}}\right) \\
& +k_{B} T\left(\sum_{i, j} B_{i j} \Gamma_{i} \Gamma_{j}\right)+\frac{2 \pi d e^{2}}{\varepsilon_{s}}\left(\sum_{i} z_{i} \Gamma_{i}\right)^{2} \\
& +\left(\frac{\varepsilon_{d} \kappa}{\pi}\right)\left(\frac{k_{B} T}{e}\right)^{2}\left[\sqrt{1+\left(\frac{2 \pi e^{2}}{\varepsilon_{d} \kappa k_{B} T}\right)^{2}\left(\sum_{i} z_{i} \Gamma_{i}\right)^{2}}-1\right]
\end{aligned}
$$

(See Table 1 for the definition of the variables.) 
Table 1. Definition of Parameters in Equations (1) AND (2)

\begin{tabular}{ll}
\hline Symbol & \multicolumn{1}{c}{ Parameter } \\
\hline$k_{B}$ & Boltzmann constant \\
$T$ & Absolute temperature \\
$a_{i}$ & Cross-sectional area of either the head \\
& group or the hydrophobic tail of \\
& surfactant $i$, depending on which one is larger \\
$r_{i}$ & Radius associated with $a_{i}$ \\
$B_{i j}$ & Second virial coefficient associated \\
& with pairwise interactions between \\
& the hydrophobic moieties of adsorbed \\
$d$ & surfactants $i$ and $j$ \\
$e$ & Stern layer thickness \\
$\varepsilon_{s}$ & Charge of a proton \\
$z_{i}$ & Dielectric constant in the Stern layer \\
$\varepsilon_{d}$ & Valence of ionic surfactant $i$ \\
$\kappa^{-1}$ & Dielectric constant in the diffuse region \\
$\Delta \tilde{\mu}_{i}^{0} / k_{B} T$ & Debye-Hückle length of the diffuse layer \\
& Grouped parameter for surfactant $i$ associated \\
& with the change in free energy involved in \\
& bringing a surfactant molecule from the \\
& bulk phase to the interface
\end{tabular}

The surface excess is also related to the equilibrium mole fraction of surfactant $i, x_{i}$, in the bulk phase below the critical micelle concentration (CMC) by:

$$
\begin{aligned}
\ln x_{i}= & \frac{\Delta \tilde{\mu}_{i}^{0}}{k_{B} T}+\ln \frac{\Gamma_{i}}{1-\sum_{j} \Gamma_{j} a_{j}}+\frac{a_{i}\left(\sum_{j} \Gamma_{j}\right)+2 \pi r_{i} \sum_{j} \Gamma_{j} r_{j}}{1-\sum_{j} \Gamma_{j} a_{j}} \\
& +\frac{\pi a_{i}\left(\sum_{j} \Gamma_{j} r_{j}\right)^{2}}{\left(1-\sum_{j} \Gamma_{j} a_{j}\right)^{2}}+2 \sum_{j} B_{i j} \Gamma_{j} \\
& +2 z_{i} \ln \left|\frac{2 \pi e^{2} z_{i} \Gamma_{i}}{\varepsilon_{d} \kappa k_{B} T}+\sqrt{\left(\frac{2 \pi e^{2} z_{i} \Gamma_{i}}{\varepsilon_{d} \kappa k_{B} T}\right)^{2}+1}\right|+\frac{4 \pi d\left(z_{i} e\right)^{2} \Gamma_{i}}{k_{B} T \varepsilon_{s}}
\end{aligned}
$$

Some of the parameters in Equations (1) and (2) can be estimated independently. $a_{C 12 E 6}$ was calculated using the method in Nikas et al. (1992). $a_{A O T}$ was estimated from the geometry of the most stable molecular orientation, calculated using HyperChem 7.0. The dielectric constant of the Stern layer, $\varepsilon_{s}$, is not a measurable quantity. Because the small but highly hydrated $\mathrm{Na}^{+}$ion usually adsorbs the least in the charged layer (Hiemenz and Rajagopalan, 1997), the adsorbed background electrolyte $\mathrm{Na}^{+}$may be neglected and the value of $d / \varepsilon_{S}$ for AOT can be assumed to equal zero. $\varepsilon_{d}$ was assumed to be the same as that for pure water, which at room temperature, equals 78.5. This assumption is reasonable for a $0.01 \mathrm{M} \mathrm{NaCl}$ aqueous solution because the addition of $0.1 \mathrm{M} \mathrm{NaCl}$ to water only decreases its dielectric constant by 1\% (Stogryn, 1971). The remaining two parameters, $B_{i j}$, and $\Delta \tilde{\mu}_{i}^{0} / k_{B} T$, were obtained by least-squares fitting the interfacial tension data sets $\left(\Pi, x_{i}\right)$ with Equations (1) and (2). The fitting procedure was detailed in the Supporting Information. The interfacial tension

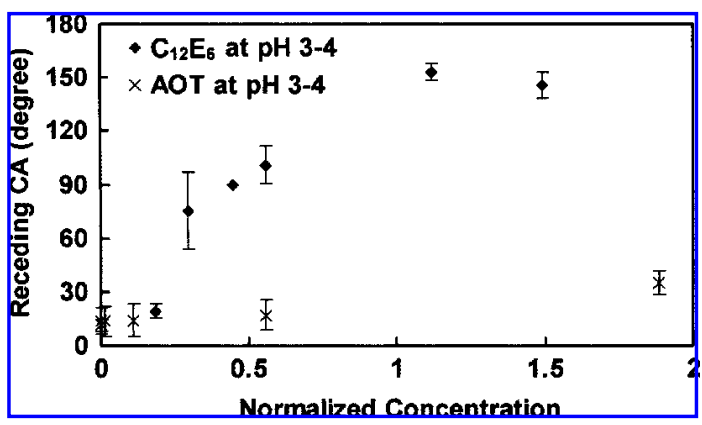

FIG. 1. Receding contact angles of tetrachloroethylene (PCE) on quartz in the single surfactant systems measured through water at $\mathrm{pH} \mathrm{3-4}$ as a function of the surfactant concentration normalized by the respective surfactant's critical micelle concentration (CMC), which occurs when $\left[\mathrm{C}_{12} \mathrm{E}_{6}\right]_{\mathrm{T}}=250 \mathrm{mM}$ or $[\mathrm{AOT}]_{\mathrm{T}}=5.63 \mathrm{mM}$. Error bars represent $95 \%$ confidence intervals.

was measured using a spinning drop tensiometer (Model 500, University of Texas), equipped with a 2-mm inner diameter tube. For each sample, three drops were measured and then averaged. The surface tension as a function of the degree of dilution for each aqueous solution was also measured using a Du Nouy ring tensiometer (Model K8, Kruss, Hamburg, Germany) with a platinum ring to ensure that the surfactant concentrations were below the CMC.

\section{Results and Discussion}

\section{Contact angle}

To examine the relationship between wettability and adsorption at the $\mathrm{s} / \mathrm{w}$ and $\mathrm{o} / \mathrm{w}$ interfaces, contact angles were measured as a function of surfactant concentration and $\mathrm{pH}$. Figure 1 shows that, as the concentration of $\mathrm{C}_{12} \mathrm{E}_{6}$ increases at low $\mathrm{pH}$, the silica surface becomes more oil-wet, eventually reversing the wettability. The contact angle continues to increase until the $\mathrm{CMC}$ is reached, after which the contact angle levels off at about $150^{\circ} \mathrm{C}$. In contrast to $\mathrm{C}_{12} \mathrm{E}_{6}$, AOT does not have any impact on the wettability of silica, which remains water-wet at concentrations up to almost two times the CMC of AOT. Figure 2 shows the contact angle variation with $\mathrm{pH}$ at fixed surfactant concentrations. AOT alone, again, shows no influence on the wettability of silica. On the other hand, $\mathrm{C}_{12} \mathrm{E}_{6}$ alone causes the silica surface to become more oil-wet at low

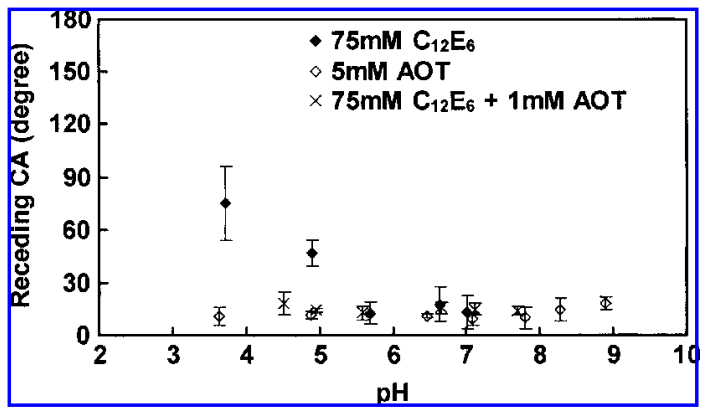

FIG. 2. Receding contact angles of PCE on quartz measured through water as a function of $\mathrm{pH}$ for three systems: (1) $\left[\mathrm{C}_{12} \mathrm{E}_{6}\right]_{\mathrm{T}}=75 \mathrm{mM}$; (2) Aerosol OT $[\mathrm{AOT}]_{\mathrm{T}}=5 \mathrm{mM}$; (3) $\left[\mathrm{C}_{12} \mathrm{E}_{6}\right]_{\mathrm{T}}=75 \mathrm{mM}$ and $[\mathrm{AOT}]_{\mathrm{T}}=1 \mathrm{mM}$. Error bars represent $95 \%$ confidence intervals. 


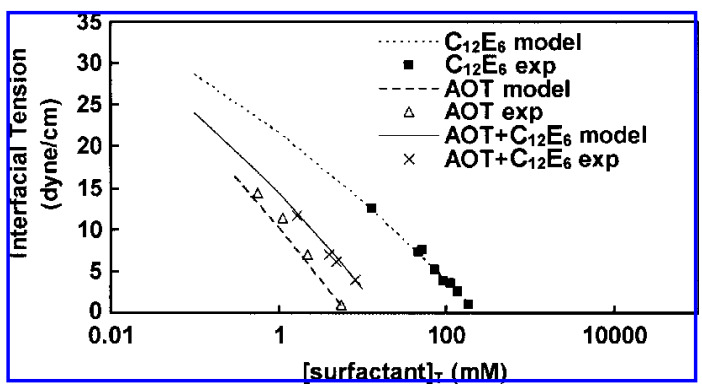

FIG. 3. Measured and simulated interfacial tensions between PCE and $0.01 \mathrm{M} \mathrm{NaCl}$ aqueous solution containing $\mathrm{C}_{12} \mathrm{E}_{6}, \mathrm{AOT}$, or $\left(\mathrm{AOT}+\mathrm{C}_{12} \mathrm{E}_{6}\right)$. In the mixed $\mathrm{AOT}+\mathrm{C} 12 \mathrm{E} 6$ system, the moles of AOT and C12E6 normalized by total moles of surfactants are 0.33 and 0.67 , respectively.

$\mathrm{pH}$ but has no influence at high $\mathrm{pH}$. Although AOT by itself does not affect wettability, the presence of AOT in conjunction with $\mathrm{C}_{12} \mathrm{E}_{6}$ decreases the impact of $\mathrm{C}_{12} \mathrm{E}_{6}$ on wettability, with the contact angle decreasing from $75^{\circ} \mathrm{C}$ without AOT to $15^{\circ} \mathrm{C}$ with AOT at $\mathrm{pH} 3-4$, thus displaying negative synergism (Hsu and Demond, 2007).

\section{Surface excess}

To obtain the surface excess at the PCE/water interface, the interfacial tension between PCE and water was measured as a function of surfactant concentration and $\mathrm{pH}$. The interfacial tensions of the systems containing AOT alone, $\mathrm{C}_{12} \mathrm{E}_{6}$ alone, or mixtures of $\mathrm{AOT}$ and $\mathrm{C}_{12} \mathrm{E}_{6}$ did not show any dependence on $\mathrm{pH}$, only on surfactant concentration (Fig. 3). Using these interfacial tension measurements, the surface excess in the single and mixed surfactant systems was obtained using Equations (1) and (2). The calculated and fitted parameter values for these equations are listed in Table 2 . The value of $\Delta \tilde{\mu}_{i}^{0} / k_{B} T$ for AOT is more negative than that for $\mathrm{C}_{12} \mathrm{E}_{6}$, consistent with previous observations that more hydrophilic surfactants tend to have more negative values (Nikas et al., 1992; Mulqueen and Blankschtein, 1999, 2002). The fitted values of $B_{i j}$ are positive for $B_{C 12 E 6-C 12 E 6}$ and $B_{A O T-C 12 E 6}$, while previously reported values were negative in air/water systems (Nikas et al., 1992; Mulqueen and Blankschtein, 1999) or zero in hydrocarbon solvent/water systems (Mulqueen and

Table 2. Parameters Used to Obtain the Surface ExCESS AT THE QuARTZ/TETRACHLOROETHYLENE/WATER INTERFACE

\begin{tabular}{llll}
\hline Parameters & & \multicolumn{1}{c}{$C_{12} E_{6}$} & \multicolumn{1}{c}{ AOT } \\
\hline Estimated & $r_{i}(\AA)$ & 3.40 & 3.63 \\
& $a_{i}\left(\AA^{2}\right)$ & 36.2 & 41.4 \\
& $d / \varepsilon_{S}$ & $\mathrm{NA}$ & 0 \\
& $z_{i}$ & 0 & -1 \\
Fitted $^{\text {a }}$ & $\kappa^{-1}(\AA)$ & $\mathrm{NA}$ & 29.73 \\
& $\Delta \tilde{\mu}_{i}^{0} / k_{B} T$ & $-15.4 \pm 1.1$ & $-21.0 \pm 0.6$ \\
& $B_{i j}\left(\AA^{2}\right)$ & $580 \pm 100$ & $-40 \pm 40$ \\
& $B_{\text {AOT-C12E6 }}\left(\AA^{2}\right)$ & $220 \pm 10$ & \\
\hline
\end{tabular}

Values presented are for the cgs unit system at $298 \mathrm{~K}$. Water contains $0.01 \mathrm{M} \mathrm{NaCl}$.

${ }^{\text {a }}$ Based on $\chi^{2}$ distribution, the reliability of the fit is $90 \%$ for $\mathrm{C}_{12} \mathrm{E}_{6}$ $80 \%$ for AOT, and $85 \%$ for the mixture.

NA, not applicable; AOT, Aerosol OT.
Blankschtein, 2002), suggesting a distinctive property in this chlorinated solvent system. As the parameter $B_{i j}$ indicates the pairwise interaction between the adsorbed surfactant hydrophobic moieties in the nonpolar medium, the positive values obtained here suggest a net repulsive interaction between the surfactant hydrocarbon chains in PCE. Previously reported experiments with polyvinyl chlorine (PVC) suggest that PVC has a basic property, attributable to the chlorine (Good and van Oss, 1992) and an acidic property, attributable to the hydrogen (Fowkes, 1987; Vrbanac and Berg, 1990). Extrapolating from this finding, the Lewis acid-base property associated with hydrogen and chlorine might be the basis of an attractive interaction between the hydrogen of the surfactant hydrocarbon chains and the chlorine of PCE. If this attractive interaction is stronger than the van der Waals forces between two surfactant hydrocarbon chains, then each hydrocarbon chain favors interaction with PCE molecules rather than with another hydrocarbon chain, leading to a separation between the surfactant hydrocarbon tails. It might be noted that this net repulsive interaction was not apparent in the PCE/water system containing AOT alone, perhaps because the net interaction between the hydrophobic tails of AOT is insignificant compared to other interactions such as electrostatic forces between the charged hydrophilic heads (Rosen and Murphy, 1986).

Figure 4a shows the calculated surface excess of AOT in the absence and presence of $\mathrm{C}_{12} \mathrm{E}_{6}$. With $\mathrm{C}_{12} \mathrm{E}_{6}$ present, the surface excess of AOT was slightly lower than in the pure AOT system. For example, at a concentration of $1 \mathrm{mM}$ AOT, the presence of $2 \mathrm{mM} \mathrm{C}_{12} \mathrm{E}_{6}$ reduced the surface excess of AOT by only $20 \%$ (from 0.012 molecules $/ \AA^{2}$ to 0.0095 molecules $/ \AA^{2}$ ). The reduction may be attributable to the increase in repulsive forces due to the adsorbed $\mathrm{C}_{12} \mathrm{E}_{6}$, as suggested by the positive value of $B_{A O T-C 12 E 6}$. Figure $4 \mathrm{~b}$ shows the surface excess of $\mathrm{C}_{12} \mathrm{E}_{6}$ in the absence and presence of AOT. Similarly, the surface excess of $C_{12} E_{6}$ was less when AOT was present yet, in this case, the reduction was considerably greater. For exam-

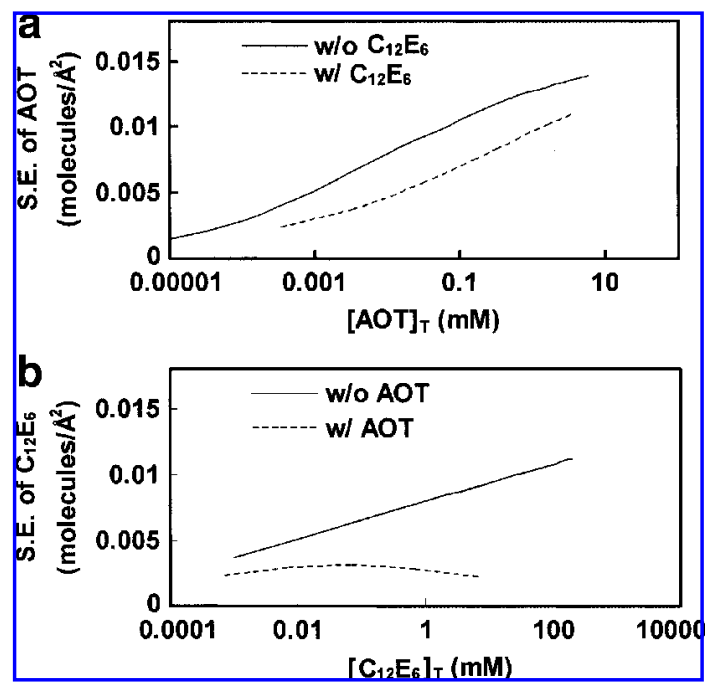

FIG. 4. Calculations of surface excess (S.E.) of (a) AOT and (b) $\mathrm{C}_{12} \mathrm{E}_{6}$ at the PCE/water interface in the single and binary surfactant systems. In the mixed AOT + C12E6 system, the moles of AOT and C12E6 normalized by total moles of surfactants are 0.33 and 0.67 , respectively. 
ple, at a concentration of $1 \mathrm{mM} \mathrm{C}_{12} \mathrm{E}_{6}$, the presence of only $0.49 \mathrm{mM}$ AOT reduced the surface excess of $\mathrm{C}_{12} \mathrm{E}_{6}$ by $69 \%$ (from 0.008 molecules $/ \AA^{2}$ to 0.0025 molecules $/ \AA^{2}$ ). These results suggest that AOT is more competitive than $C_{12} E_{6}$ in the mixed monolayer. Consequently, the mixed monolayer tends to be dominated by AOT unless the concentration of AOT is far below that of $\mathrm{C}_{12} \mathrm{E}_{6}$.

\section{Adsorption isotherms}

Adsorption isotherms of $\mathrm{C}_{12} \mathrm{E}_{6}$ and AOT onto quartz from the aqueous phase were measured. Regardless of whether measurable concentrations of $\mathrm{C}_{12} \mathrm{E}_{6}$ were present in the aqueous phase or not, there was no detectable amount of AOT adsorption even at concentrations above the CMC of AOT. The negligible adsorption of AOT onto quartz is probably due to the same charge electrostatic repulsion between AOT and the quartz surface. The adsorption isotherms for $\mathrm{C}_{12} \mathrm{E}_{6}$ at two different $\mathrm{pH}$ values in the absence of AOT are shown in Figure 5. Consistent with the behavior reported for other nonionic surfactants (Penfold et al., 1997), the adsorption of $\mathrm{C}_{12} \mathrm{E}_{6}$ at low $\mathrm{pH}$ is higher than that at high $\mathrm{pH}$, reflecting the fact that the adsorption of $\mathrm{C}_{12} \mathrm{E}_{6}$ is associated with the number of hydroxyl groups on the quartz surface. At each value of $\mathrm{pH}$, the adsorption increases with increasing $\mathrm{C}_{12} \mathrm{E}_{6}$ concentration, reaching a plateau around the $\mathrm{CMC}$. The saturated adsorption density of $\mathrm{C}_{12} \mathrm{E}_{6}$ on quartz is 2.5 molecules $/ \mathrm{nm}^{2}$ or $40 \AA^{2} /$ molecule at pH 3-4 and 0.5 molecules $/ \mathrm{nm}^{2}$ or $200 \AA^{2} /$ molecule at $\mathrm{pH} 7-8$. These data compare well with the values of $34 \AA^{2} /$ molecule at pH 2.4 and $215-270 \AA^{2} /$ molecule at pH 7 reported by Penfold et al. (1997). Although the saturated adsorption density at $\mathrm{pH} 3-4$ is comparable to the size of the hydrophilic head of $\mathrm{C}_{12} \mathrm{E}_{6}, 36.3 \AA^{2} /$ molecule (Mulqueen and Blankschtein, 2002), the adsorption configuration is not a compact monolayer. Specular neutron reflection and ellipsometry studies of $\mathrm{C}_{12} \mathrm{E}_{6}$ adsorption on silica have shown that the adsorption thickness increases from almost zero to a double layer at a low adsorption density and the change occurs within a narrow surfactant concentration range (Tiberg et al., 1994; Penfold et al., 1997). As a result of the double-layer structure, oxyethylene groups are exposed at the silica surface over the majority of the range of adsorption density.

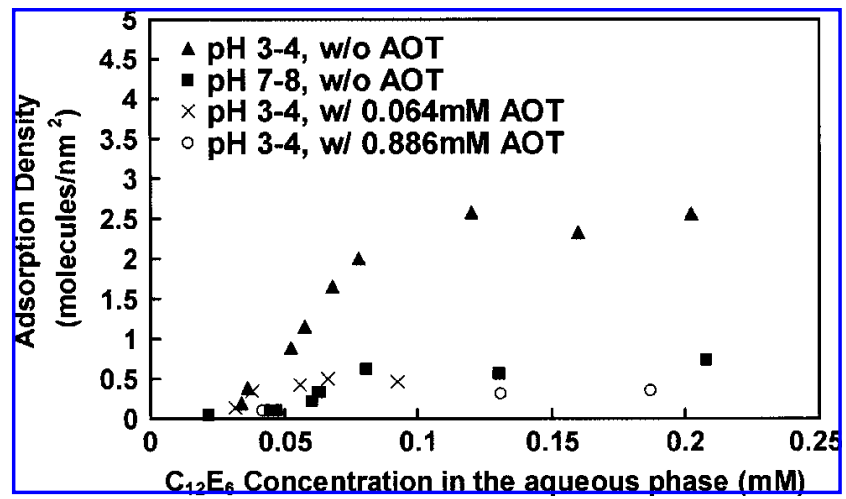

FIG. 5. Adsorption isotherms of $\mathrm{C}_{12} \mathrm{E}_{6}$ on quartz at $\mathrm{pH}=3-4$ and $\mathrm{pH}=7-8$ in the absence or presence of AOT. The plateau was reached around the $C M C$ of $\mathrm{C}_{12} \mathrm{E}_{6}$, which occurs at $0.07 \mathrm{mM}$ in $0.01 \mathrm{M} \mathrm{NaCl}$ aqueous solution for the $\mathrm{C}_{12} \mathrm{E}_{6}$ system or before this value in the mixed surfactant systems.
Also shown in Fig. 5 are the adsorption isotherms of $\mathrm{C}_{12} \mathrm{E}_{6}$ in the presence of AOT. The data were all measured below the mixed $\mathrm{CMC}$, except for the highest and the two highest $\mathrm{C}_{12} \mathrm{E}_{6}$ concentrations in the presence of $0.064 \mathrm{mM}$ AOT and $0.886 \mathrm{mM}$ AOT, respectively. These results show that the presence of AOT reduced the adsorption of $\mathrm{C}_{12} \mathrm{E}_{6}$ on silica. Below the mixed $\mathrm{CMC}$, the reduced adsorption of $\mathrm{C}_{12} \mathrm{E}_{6}$ in the presence of AOT might be due to the salting-in effect. As previously noted (Clunie and Ingram, 1983), the presence of an electrolyte, such as an organic salt (Ray and Nemethy, 1971) like AOT, may decrease the adsorption of a nonionic surfactant on quartz. The dissolution of a nonionic surfactant in water requires energy to create cavities in the aqueous phase to accommodate the hydrophobic tails; the dissolved organic salt may help to lower the required energy, facilitating $\mathrm{C}_{12} \mathrm{E}_{6}$ dissolution in water and, in turn, lowering its adsorption on quartz.

\section{Interpretation of wettability changes}

To analyze why the contact angle increases with $\mathrm{C}_{12} \mathrm{E}_{6}$ concentrations (Fig. 1), we first examined the surfactant coverage of each interface to determine the relative significance of considering the surfactant adsorption at that interface. According to Fig. $4 \mathrm{~b}$, the density of $\mathrm{C}_{12} \mathrm{E}_{6}$ at the PCE/water interface is $0.012-0.013$ molecules $/ \AA^{2}$ at the CMC $\left(\left[\mathrm{C}_{12} \mathrm{E}_{6}\right]_{\mathrm{T}}=\right.$ $250 \mathrm{mM})$. As the cross-sectional area of $\mathrm{C}_{12} \mathrm{E}_{6}$ is about $36.2 \AA^{2}$ /molecule (Table 2), the interfacial coverage is around $50 \%$ at the $\mathrm{CMC}$ of $\mathrm{C}_{12} \mathrm{E}_{6}$. Similarly, the coverage of the silica/ water interface (Fig. 5) is also about $50 \%$ due to bilayer adsorption. Thus, the coverage of both interfaces is similar.

A schematic illustration depicting three possible interactions is shown in Fig. 6. If one were to explain the wettability change in Fig. 1 solely based on the interaction between PCE and the surfactants at the silica/water interface (denoted by

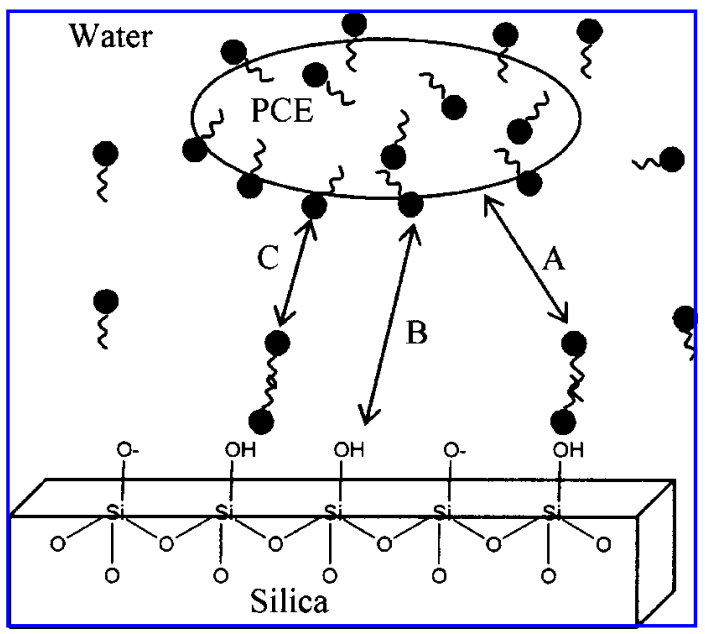

FIG. 6. Diagram showing three interactions between PCE and silica both immersed in water that could potentially change the system's wettability. The tadpole-like molecules are $\mathrm{C}_{12} \mathrm{E}_{6}$ with a hydrophilic head and a hydrophobic tail. The interaction between PCE and surfactant molecules adsorbed at the water/silica interface is denoted by $\mathbf{A}$; the one between silica and the surfactant molecules adsorbed at the water/PCE interface is denoted by $\mathbf{B}$; the one between the surfactant molecules adsorbed at both water/silica and water PCE interfaces is denoted by $\mathbf{C}$. 
Fig. 6A), the configuration of bilayer adsorption would not support an attractive interaction because what is exposed at the silica surface are the hydrophilic heads of the surfactants. Alternatively, the wettability change could be attributed to hydrogen bonding between the silanol groups $(-\mathrm{SiOH})$ of silica surface and the surface excess at the PCE/water interface (denoted by Fig. 6B). This explanation might hold at low surfactant concentrations when the surface excess is the limiting factor; however, it fails at high surfactant concentrations. Because the silica/water interface also adsorbs surfactants through the silanol groups, the silanol sites become limited as the surfactant concentration increases and thus a decrease in the contact angle would be expected. However, such a decrease was not observed. Consequently, additional interactions must occur to explain the wettability changes presented in Fig. 1, especially at high surfactant concentrations.

To explain the experimental observations, a third interaction between the adsorbed surfactant molecules at both the $\mathrm{PCE} /$ water and the silica/water interfaces (denoted by Fig. 6C) is hypothesized. It has been found that an entropy-driven attraction exists between the oxyethylene groups of nonionic surfactants (Kjellander, 1984; Claesson et al., 1986). Because the outer part of the adsorbed $\mathrm{C}_{12} \mathrm{E}_{6}$ molecules at both interfaces is a hydrophilic oxyethylene group, more adsorbed $\mathrm{C}_{12} \mathrm{E}_{6}$ at both interfaces result in a stronger attraction between PCE and silica, and in turn, a larger contact angle.

This interaction can also explain the contact angle variation with $\mathrm{pH}$ shown in Fig. 2 . In the system containing only $\mathrm{C}_{12} \mathrm{E}_{6}$, the surface excess did not vary with $\mathrm{pH}$, but the adsorption of $\mathrm{C}_{12} \mathrm{E}_{6}$ on silica increased with decreasing $\mathrm{pH}$ (Fig. 5). Because greater adsorption of $\mathrm{C}_{12} \mathrm{E}_{6}$ at the $\mathrm{PCE} /$ water or the silica/ water interface increases the attraction between PCE and silica, the silica became more oil-wet (as indicated by the increase in the contact angle) with decreasing $\mathrm{pH}$. Furthermore, the proposed interpretation also successfully explains the contact angle changes in the mixed surfactant systems. In Fig. 2 , introducing AOT into a solution of $\mathrm{C}_{12} \mathrm{E}_{6}$ decreased the oilwetness of the quartz. Because the adsorption of $\mathrm{C}_{12} \mathrm{E}_{6}$ is reduced significantly in the presence of AOT, both at the $\mathrm{o} / \mathrm{w}$ interface (Fig. 4) and at the s/w interface (Fig. 5), the attraction between PCE and the quartz surface is reduced. In addition, the surface excess of AOT at the o/w interface contributes a repulsive force relative to the negatively charged quartz surface, further reducing oil-wetness. Further work reported in Hsu (2005) suggested that this interaction is also present in other AOT $/ \mathrm{C}_{12} \mathrm{E}_{\mathrm{x}}$ systems.

\section{Conclusions}

Changes in wettability due to the presence of surface-active solutes have often been interpreted in terms of surfactant adsorption at the oil/water interface (surface excess) or at the silica/water interface. The data presented here suggest that the interpretation of wettability may require a consideration of adsorption at both interfaces and the subsequent interaction of the molecules sorbed at both interfaces. If a DNAPL waste contains only anionic surfactants, the system may remain water-wet across a wide $\mathrm{pH}$ range. If the waste contains a sufficiently high concentration of nonionic surfactants, the system can potentially turn oil-wet, especially at low $\mathrm{pH}$. This change in wettability appears to be attributable to the interaction between the oxyethylene groups of the nonionic sur- factant molecules sorbed at the two interfaces, resulting in a stronger attraction between PCE and silica.

Because DNAPL wastes often contain high concentrations of surfactants, this new mechanism may be critical in explaining field observations. For example, Dwarakanath et al. (2002) observed that by adding anionic surfactants, the wettability of alluvium in contact with a real NAPL waste actually turned more water-wet, leading to a higher DNAPL mobility. Based on the research reported here, this phenomenon may have occurred as a result of the added anionic surfactant adsorbing at the DNAPL/water interface, decreasing the affinity of the DNAPL for the negatively charged quartz surface. In addition, the anionic surfactant may reduce the adsorption of the nonionic surfactant at both the silica/water and DNAPL/water interfaces, further decreasing the entropy-driven attraction and leading to a less oil-wet condition. Thus, such mechanistic knowledge can lead to a better understanding of the sometimes perplexing behavior of DNAPL wastes in the subsurface and the design of effective remediation strategies.

\section{Acknowledgments}

The authors wish to thank Tom Yavaraski for his help with the chemical analyses. This research was supported by Grant No. DE-FG07-96ER14702 from Environmental Management Science Program, United States Department of Energy (DOE). Any opinions, findings, conclusions, or recommendations expressed herein are those of the authors and do not necessarily reflect the views of DOE.

\section{Author Disclosure Statement}

No completing financial interests exist.

\section{References}

Buckley, J.S., Takamura, K., and Morrow, N.R. (1987). Influence of electrical surface charges on the wetting properties of crude oils. SPE 16964, presented at the 62nd Annual Technical Conference and Exhibition of the Society of Petroleum Engineering, Dallas, TX, September 27-30, p. 317.

Cheng, P.W.P. (1990). Automation of axisymmetric drop shape analysis using digital image processing. PhD dissertation, Univ. Toronto, Toronto, Ontario, Canada.

Claesson, P.M., Kjellander, R., Stenius, P., and Christenson, H.K. (1986). Direct measurement of temperature-dependent interactions between non-ionic surfactant layers. J. Chem. Soc. Faraday Trans. I 82, 2735.

Clunie, J.S., and Ingram, B.T. (1983). Adsorption of nonionic surfactants. In G.D. Parfitt and C.H. Rochester, Eds., Adsorption from Solution at the Solid/Liquid Interface. New York: Academic Press, p. 105.

Cowell, M.A., Kibbey, T.C.G., Zimmerman, J.B., and Hayes, K.F. (2000). Partitioning of ethoxylated nonionic surfactants in water/NAPL systems: Effects of surfactant and NAPL properties. Environ. Sci. Technol. 34, 1583.

Demond, A.H., Desai, F.N., and Hayes, K.F. (1994). Effect of cationic surfactants on organic liquid-water capillary pressuresaturation relationships. Water Resour. Res. 30, 333.

Dubey, S.T., and Doe, P.H. (1993). Base number and wetting properties of crude oils. SPE Reservoir Eng. 8, 195.

Dwarakanath, V., Jackson, R.E., and Pope, G.A. (2002). Influence of wettability on the recovery of NAPLs from alluvium. Environ. Sci. Technol. 36, 227. 
Fowkes, F.M. (1987). Role of acid-base interfacial bonding in adhesion. I. Adhes. Sci. Technol. 1, 7.

Good, R.J., and van Oss, C.J. (1992). The modern theory of contact angles and the hydrogen bond components of surface energies. In M.E. Schrader and G. Loed, Eds., Modern Approach to Wettability: Theory and Application. New York: Plenum Press, p. 1.

Harrold, G., Goody, D.C., Lerner, D.N., and Leharne, S.A. (2001). Wettability changes in trichloroethylene-contaminated sandstone. Environ. Sci. Technol. 35, 1504.

Hiemenz, P.C., and Rajagpalan, R. (1997). Principles of Colloid and Surface Chemistry. New York: Marcel Dekker.

Hsu, H.L. (2005). Determination of interfacial tension and contact angle of dense non-aqueous phase liquid waste mixtures. Ph.D. dissertation, University of Michigan, Ann Arbor, MI.

Hsu, H.L., and Demond, A.H. (2007). Influence of organic acid and organic base interactions on interfacial properties in NAPL-water systems. Environ. Sci. Technol. 41, 897.

Kjellander, R. (1984). On the image-charge model for the hydration force. J. Chem. Soc. Faraday Trans. II 80, 1323.

Lord, D.L., Demond, A.H., and Hayes, K.F. (2000). Effects of organic base chemistry on interfacial tension, wettability, and capillary pressure in multiphase subsurface waste systems. Transport Porous Media 38, 79.

Lord, D.L., Demond, A.H., Salehzadeh, A., and Hayes, K.F. (1997). Influence of organic acid solution chemistry on subsurface transport properties. 2. Capillary pressure-saturation. Environ. Sci. Technol. 31, 2052.

Myers, D. (1992). Surfactant Science and Technology. New York: VCH Publishers.

Mulqueen, M., and Blankschtein, D. (1999). Prediction of equilibrium surface tension and surface adsorption of aqueous surfactant mixtures containing ionic surfactants. Langmuir 15, 8832.

Mulqueen, M., and Blankschtein, D. (2002). Theoretical and experimental investigation of the equilibrium oil-water interfacial tensions of solutions containing surfactant mixtures. Langmuir 18, 365.
National Research Council. (2004). Contaminants in the Subsurface: Source Zone Assessment and Remediation. Washington, DC: National Academies Press.

Nikas, Y.J., Puvvada, S., and Blankschtein, D. (1992). Surface tension of aqueous nonionic surfactant mixtures. Langmuir 8 , 2680.

O'Carroll, D.M., Bradford, S.A., and Abriola. L.M. (2004). Infiltration of PCE in a system containing spatial wettability variations. J. Contam. Hydrol. 73, 39.

Penfold, J., Staples, E.J., Tucker, I., and Thompson, L.J. (1997). Adsorption of mixed cationic and nonionic surfactants at the hydrophilic silicon surface from aqueous solution: Studied by specular neutron reflection. Langmuir 13, 6638.

Ray, A., and Nemethy, G. (1971). Effects of ionic protein denaturants on micelle formation by nonionic detergents. $\underline{\text {. Am. }}$. Chem. Soc. 93, 6787.

Rosen, M.J., and Murphy, D.S. (1986). Synergism in binary mixtures of surfactants V. Two-phase liquid-liquid systems at low surfactant concentrations. J. Colloid Interface Sci. 110, 224.

Speight, J.D. (1991). The Chemistry and Technology of Petroleum. New York: Marcel Dekker.

Standal, S., Haavik, J., Blokhus, A.M., and Skauge, A. (1999). Effect of polar organic components on wettability as studied by adsorption and contact angles. L. Petrol. Sci. Eng. 24, 131.

Stogryn, A. (1971). Equations for calculating the dielectric constant of saline water. IEEE Trans. Microwave Theory Tech. August, 733.

Tiberg, F., Jönsson, B., Tang, J., and Lindman, B. (1994). Ellipsometry studies of the self-assembly of nonionic surfactants at the silica-water interface: Equilibrium aspects. Langmuir 10, 2294.

Vrbanac, M.D., and Berg, J.C. (1990). The use of wetting measurements in the assessment of acid-base interactions at solidliquid interfaces. J. Adhes. Sci. Technol. 4, 255.

Zheng, J., Behrens, S.H., Borkovec, M., and Powers, S.E. (2001). Prediction of the wettability of quartz surfaces exposed to dense nonaqueous phase liquids. Environ. Sci. Technol. 35, 2207. 
